\title{
A case series and review on pediatric thyroid nodules
}

\begin{abstract}
Thyroid nodules have a higher risk of malignancy in children and hence need close monitoring. Primary care providers often obtain the initial thyroid work up. Once there patients are referred to specialists, primary providers are unsure about subsequent management and follow up. We present here three cases of thyroid nodules with different initial presentation, diagnosis and management. This article provides a good brief summary about thyroid nodule and reiterates the importance of long term follow up of these patients by primary care provider and endocrinologists.
\end{abstract}

Keywords: thyroid nodules, thyroid cancer, pediatrics
Volume 8 Issue I - 2020

\author{
Anju Sukumaran, ' Valiparambil B Praveen \\ Kumar $^{2}$ \\ 'Department of Pediatric Endocrinology, University of \\ Mississippi Medical Center 2500 N State St, USA \\ 2Pediatrician, Jackson Hinds Comprehensive Health, USA
}

Correspondence: Anju Sukumaran, Department of Pediatric Endocrinology, University of Mississippi Medical Center $2500 \mathrm{~N}$ State St, Jackson, MS, 39216, USA, Tel 60I 984 5246, Fax 601815 3672, Email asukumran@umc.edu

Received: December 24, 2019 | Published: January 31, 2020
Abbreviations: DTC, differentiated thyroid cancer; PTC, papillary thyroid carcinoma; FTC, follicular thyroid carcinoma, MTC, medullary thyroid carcinoma; ATA, american thyroid association; PTMC, Papillary thyroid micro carcinoma

\section{Introduction}

Parents often bring their children to the Pediatrician's office with concerns about possible thyroid dysfunction. Often an online search or social media posts suggest that thyroid conditions can be the cause of a plethora of nonspecific complaints such as excessive weight gain, fatigue, irregular menstrual periods and behavioral problems. Parents who are anxious to find an explanation for their child's issues often seem almost hopeful that a treatable thyroid condition might be the answer that they are seeking. Other families have concerns about a strong family history of thyroid disease or other autoimmune conditions. For these reasons, simple thyroid lab testing is commonly ordered to address these concerns. Generally, when thyroid function testing shows abnormalities or when a goiter is noted on exam, additional testing is performed which often includes a thyroid ultrasound. Children who are found to abnormal lab or imaging results are often referred to Pediatric Endocrinologists. This article focuses on the evaluation of children who are found to have thyroid imaging which indicates the presence of a single or multiple thyroid nodules. An outline for approach and management of thyroid nodules in children is presented.

\section{Illustrative cases}

This case series report 3girls who had thyroid nodules but with different initial presentations, diagnosis and management (Table 1).

First case is a 12 year old African American girl who presented with goiter. She had negative autoimmune thyroid disease or family history of thyroid disease. On exam, she had goiter, a nodule felt on right thyroid lobe with no lymphadenopathy. She had normal thyroid labs. Biopsy of nodule resulted follicular lesion of undetermined significance. She underwent right thyroid lobectomy and final pathology was follicular adenoma.

Second case is a 12-year-old White girl who presented with weight gain. Her mother and grandmother had hypothyroidism. She was started on levothyroxine due to Hashimotos hypothyroidism. On exam, she had goiter but no nodules felt. Initial ultrasound did not show nodules but repeat did and biopsy confirmed papillary thyroid carcinoma. She underwent total thyroidectomy with paratracheal lymph node dissection. Her iodine uptake scan was negative for uptake and currently continuing levothyroxine replacement and close monitoring of thyroglobulin levels.

Third, is an African American 17year old girl who presented with headache. She had no autoimmune thyroid disease or family history of thyroid disease. She had normal thyroid exam but TSH was suppressed with normal free T4 but elevated T3 levels. Her thyroid ultrasound showed a nodule with increased iodine uptake. She underwent left thyroidectomy for large toxic adenoma.

\section{Discussion}

Palpable thyroid nodules are less common in children than adults but sonographic and or pathological abnormalities are common $(0.2-$ $5 \%$ of children, $13 \%$ of adolescents). ${ }^{1}$ Non palpable thyroid nodules detected by imaging have the same risk for differentiated thyroid cancer (DTC) as a palpable thyroid nodules of similar size. ${ }^{2}$ The risk for malignancy in thyroid nodules in children is higher at $22-26 \%$ as compared to $7-15 \%$ in adults. ${ }^{3}$ Survival from pediatric thyroid cancer is excellent, with reported 30-year survival rates of $99 \%$ to $100 \%$ and $91 \%$ for papillary and non-papillary thyroid carcinoma, respectively. ${ }^{4}$

Differential diagnosis for thyroid nodules includes benign (75\%) and malignant causes $(25 \%)$. Benign nodules include colloid or adenomatoid nodule, follicular or Hurthle cell adenoma, and simple cyst (which are lined by benign epithelial cells). Malignancy affecting thyroid nodules are papillary thyroid carcinoma (PTC), follicular thyroid carcinoma (FTC), and medullary thyroid carcinoma (MTC). Poorly differentiated variants and anaplastic thyroid carcinomas are rare in children.

The risk factors for thyroid nodules in children are listed in Table $2{ }^{5}$ Though the risk for cancer is 2.5 fold higher with a family history of benign thyroid disease and 4fold higher with a family history of thyroid cancer, a routine neck palpation by an experienced provider might be sufficient monitoring. According to Bauer et al, an ultrasound should be performed if the gland feels suspicious or if there is a high 
risk family history. American Thyroid Association (ATA) guidelines recommend ultrasound with autoimmune thyroiditis only if there is a suspicion about a nodule or abnormal lymphadenopathy on physical examination.
An initial evaluation, management and follow up for a thyroid nodule is shown in Figure 1. The following recommendations are mostly adapted from American Thyroid Association (ATA) guidelines published in $2015 .^{\circ}$

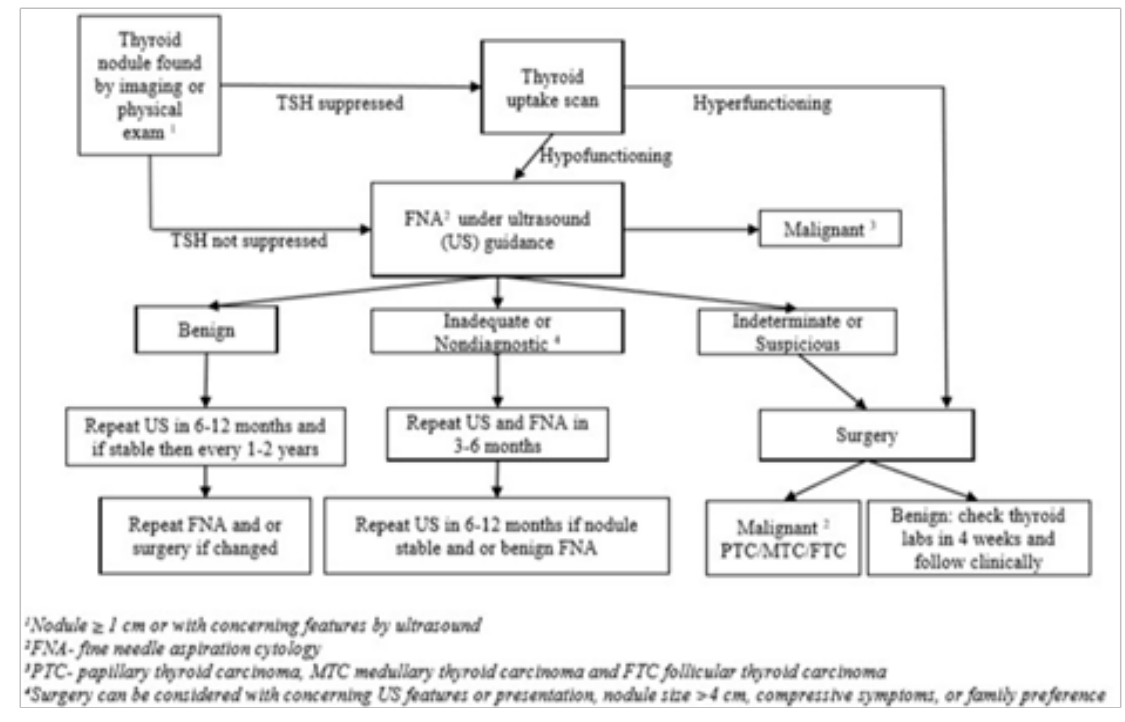

Figure I Initial evaluation, treatment, and follow up of the pediatric thyroid nodule.

\section{Ultrasound features}

Nodular characteristics and clinical context should be used to identify the need for FNA. Features such as hypo echogenicity, irregular margins, increased intranodular blood flow, presence of microcalcifications, and abnormal cervical lymph nodes are more common in malignant lesions. Ultrasound guided fine needle aspiration (FNA) should be performed if thyroid nodule is more than $10 \mathrm{~mm}$, unless purely cystic and for nodules $5-10 \mathrm{~mm}$ with suspicious features. ${ }^{6}$

\section{Cytopathology findings}

These are categorized according to The Bethesda System for Reporting Thyroid Cytopathology. In this six-tier system, FNA results are reported as
a. Nondiagnostic or unsatisfactory;
b. Benign;
c. Atypia or follicular lesion of undetermined significance;
d. Follicular/Hurthle neoplasm or suspicious for follicular/Hurthle neoplasm;
e. Suggestive of malignancy;
f. Malignant. ${ }^{7}$

Due to increased probability of malignancy among indeterminate categories in children, a lobectomy plus isthmusectomy is recommended.

Follow-up of benign cytology should be risk stratified according to risk factors as well as the ultrasound features. Highly suspicious thyroid nodules in children should be removed despite benign cytology. Thyroid nodules with low to intermediate suspicion should undergo repeat ultrasound at 12 months but delaying surveillance up to 24 months may be reasonable in large, predominantly cystic nodules. ${ }^{8}$

\section{Need for thyroid replacement with nodules}

There are data supporting the efficacy of thyroid replacement therapy to reduce the size and risk of subsequent nodule formation, but there are no data to weigh this potential benefit against the potential risks of long-term suppression therapy.

In patients with compressive symptoms or a history of radiation exposure the benefits of thyroid replacement therapy may be more apparent.

\section{Nodules with suppressed TSH}

If nodule is associated with a suppressed TSH, a thyroid scintigraphy should be pursued. Increased uptake within the nodule is consistent with autonomous nodular function. Surgical resection, most commonly lobectomy, is the recommended approach for most autonomous nodules in children and adolescents.

\section{Benign lesions}

These should be followed by serial ultrasound and undergo repeat FNA if suspicious features develop or the lesion continues to grow. Indications for surgery are as described above in Figure 1.

\section{Cystic lesions}

FNA should be considered for lesions that have more than $50 \%$ solid component, if the solid component has concerning ultrasound features, or if there are abnormal cervical lymph nodes. For children with large cystic lesions, lobectomy may be reasonable based on symptoms or for cosmetic purposes. 
Table I Illustrative cases

\begin{tabular}{|c|c|c|c|}
\hline & Case I & Case 2 & Case 3 \\
\hline Age & 12 & 12 & 17 \\
\hline Sex & Girl & Girl & Girl \\
\hline Ethnicity & African American & White & African American \\
\hline Chief Complaint & Goiter & Weight gain & Headache \\
\hline Thyroid symptoms & None & Rest negative & None \\
\hline $\begin{array}{l}\text { Family history of thyroid } \\
\text { disease }\end{array}$ & Negative & $\begin{array}{l}\text { Mother \& grandmother with } \\
\text { hypothyroidism }\end{array}$ & Negative \\
\hline Autoimmunity & Negative & Hashimotos + & Negative \\
\hline $\begin{array}{l}\text { Vitals (heart rate } \\
\text { \&blood pressure) }\end{array}$ & Normal & Normal & Mild tachycardia \\
\hline Physical Examination & $\begin{array}{l}\text { Goiter, nodule on right } \\
\text { side non tender }\end{array}$ & Goiter, no nodules & Normal thyroid exam \\
\hline Lymphadenopathy neck & None & Upper cervical & None \\
\hline Labs & Normal TSH' and & $\begin{array}{l}\text { Elevated TSH at } 153 \text { low free T4 } \\
\text { at } 0.1\end{array}$ & Low TSH 0.0I \\
\hline \multirow[t]{2}{*}{ Free T4(0.9-I.6ng/dl) } & Free T4 & & Free T4 I.4 \\
\hline & & & T3 2.19(0.8-2ng/ml) \\
\hline $\begin{array}{l}\text { Thyroid replacement } \\
\text { medication }\end{array}$ & Not started & $\begin{array}{l}\text { Synthroid II } 2 \mathrm{mcg} \\
\text { once daily }\end{array}$ & None \\
\hline \multirow[t]{6}{*}{$\begin{array}{l}\text { Ultrasound Thyroid } \\
\text { (dimensions in } \mathrm{cm} \text { ) }\end{array}$} & Right lobe: & Right lobe: $7.4 \times 3.6 \times 3.6$ & Right lobe: \\
\hline & $5.58 \times 3.29 \times 4.3$ & Left lobe: & $4 .|7 x| .33 \times 1.10$ \\
\hline & $\begin{array}{l}\text { Nodule right side: } \\
5.0 \times 3.8 \times 3.1\end{array}$ & $7.5 \times 3.6 \times 3.2$ & Left lobe: \\
\hline & Left lobe: & Isthmus: I.5 & $5.64 \times 2.17 \times 2.22$ \\
\hline & $4.7 \times 1.1 \times 1.2$ & & Nodule Left: \\
\hline & & & $3.50 \times 2.27 \times 2.53$ \\
\hline \multirow[t]{2}{*}{ Nodule features } & Solid and isoechoic & $\begin{array}{l}\text { Very hyper vascular Coarse } \\
\text { calcifications }+ \text { No focal nodule }\end{array}$ & $\begin{array}{l}\text { Solid hyperechoic, heterogeneous nodule with } \\
\text { internal vascularity }\end{array}$ \\
\hline & & \multicolumn{2}{|c|}{$\mathrm{LN}^{2} 1.7-2 \mathrm{~cm}$ bilaterally Repeat in 6 months showed nodule $1.8 \mathrm{~cm}$ right side. } \\
\hline FNA $^{3}$ Thyroid and & $\begin{array}{l}\text { Follicular lesion of } \\
\text { undetermined }\end{array}$ & \multirow[t]{2}{*}{ Papillary thyroid carcinoma } & \multirow[t]{2}{*}{ Indeterminate } \\
\hline Pathology report & significance & & \\
\hline Other imaging & None & $\begin{array}{l}\text { CT neck and chest: no concerning } \\
\text { pulmonary or neck LN }\end{array}$ & $\begin{array}{l}\mathrm{I}-\mathrm{I} 23^{4} \text { uptake with increased uptake in left lobe } \\
\text { and suppression in right lobe. }\end{array}$ \\
\hline \multirow[t]{2}{*}{ Treatment } & $\begin{array}{l}\text { Right thyroid } \\
\text { lobectomy }\end{array}$ & $\begin{array}{l}\text { Total thyroidectomy with dissection } \\
\text { of para }\end{array}$ & Left thyroidectomy \\
\hline & & tracheal LN & \\
\hline Final Pathology & Follicular adenoma & $\begin{array}{l}\text { Papillary thyroid cancer TINO- low } \\
\text { risk }\end{array}$ & Large toxic adenoma \\
\hline \multirow[t]{3}{*}{ Post-surgery labs } & $\begin{array}{l}\text { Normal thyroid, } \\
\text { calcium and } \mathrm{PTH}^{5}\end{array}$ & Restarted Synthroid & Normal thyroid labs \\
\hline & & Normal calcium, PTH & \\
\hline & & I-I23 scan- no uptake & \\
\hline Follow up & & Thyroglobulin 0.1 & \\
\hline
\end{tabular}

'TSH- thyroid stimulating hormone $(0.5-4.5 \mathrm{mclU} / \mathrm{ml})$;

${ }^{2} \mathrm{LN}$ - lymph nodes;

${ }^{3}$ FNA- fine needle aspiration;

${ }^{4}$ I-I23- iodine I 23 isotope;

${ }^{5} \mathrm{PTH}$ - parathyroid hormone. 
Table 2 The risk factors for thyroid nodules in children ${ }^{5}$

\begin{tabular}{ll}
\hline I & Family history of thyroid nodules or thyroid cancer \\
2 & lodine deficiency \\
3 & Radiation exposure especially in childhood cancer survivors \\
4 & History of thyroid disease like autoimmunity \\
5 & Elevated serum thyroid stimulating hormone (TSH) \\
6 & $\begin{array}{l}\text { Several genetic syndromes like APC associated familial } \\
\text { adenomatous polyposis, DICER I syndrome, PTEN hamartoma } \\
\text { tumor syndrome etc }\end{array}$
\end{tabular}

\section{Multinodular goiter}

Each thyroid nodule carries an independent risk for developing differentiated thyroid cancer (DTC). FNA should be performed on any thyroid nodules with suspicious ultrasound features but does not need to be performed on all nodules that have the same ultrasound features. ${ }^{9}$

\section{Papillary thyroid carcinoma}

Initial treatment approach for PTC is total thyroidectomy with or without lymph node dissection based on preoperative staging which can include neck ultrasound with FNA of abnormal lymph nodes, serum thyroglobulin and antibody level, chest X-ray, and CT neck and chest with contrast. Utilizing high-volume thyroid surgeons can reduce the rate of complications of thyroidectomy which are transient or permanent hypoparathyroidism $(5 \%-15 \%)$, recurrent laryngeal nerve damage, spinal accessory nerve injury, and Horner syndrome $(1 \%-6 \%)(14)$. The utility of intact parathyroid hormone level is fairly well established with a level of $<10-15 \mathrm{pg} / \mathrm{mL}$ correlating with an increased risk to develop clinically significant hypocalcemia and thus help to stratify patients who would benefit from more intensive monitoring and treatment with calcium and calcitriol. ${ }^{131}$ I radioactive iodine ablation therapy is indicated for treatment of persistent local or nodal disease that cannot be resected and for known or presumed distant metastases.

The short-term side effects of ${ }^{131} I$ are damage to tissues that incorporate iodine, resulting in sialadenitis, xerostomia, dental caries, stomatitis, ocular dryness, and nasolacrimal duct obstruction. ${ }^{10}$ In post pubertal males, a transient rise in follicle-stimulating hormone is common and may persist for up to 18 months after ${ }^{131} \mathrm{I}$ exposure. Transient amenorrhea and menstrual irregularities are reported in up to $17 \%$ of females under the age of 40 years. ${ }^{11}$ Acute suppression of bone marrow may occur but hematologic parameters usually normalize within 60days after ${ }^{131} \mathrm{I}$ exposure. ${ }^{12}$ Unfortunately, there is a lack of long-term data to define a safe activity of ${ }^{131} \mathrm{I}$,

and additional study is clearly warranted to determine the risks for secondary malignancies later in life. There is also an increased risk for pulmonary fibrosis in patients who had pulmonary metastasis and had ${ }^{131}$ I. Patients with thyroid cancer are categorized into low or intermediate or high risk based on extent of tumor and kept on TSH suppressive therapy using levothyroxine. They are monitored using ultrasound neck, thyroglobulin and anti-thyroglobulin antibody levels.

Papillary thyroid micro carcinoma (PTMC) are defined as lesions with focus of $1 \mathrm{~cm}$ or less involvement. Lymph node metastases are more common in patients less than 19years of age with PTMC
(72.5\%) suggesting that they might not be indolent and warrant continued follow-up.

\section{Follicular thyroid carcinoma}

FTC currently represents $10 \%$ or less of thyroid cancer cases diagnosed in children or young adults and the prevalence appears to be decreasing over time..$^{13,14}$ Iodine deficiency is the one clear risk factor for the development of FTC. FNA usually reports as indeterminate result and not sufficient for making the diagnosis of FTC..$^{15}$ Patients with clear evidence of vascular invasion, distant metastasis, and/ or tumor size $>4 \mathrm{~cm}$ should be treated with total thyroidectomy and with radioactive iodine ablation. In all children diagnosed with FTC, genetic counseling and testing for germline PTEN mutations should be considered.

\section{Medullary thyroid carcinoma}

MTC is seen with multiple endocrine neoplasia (MEN) 2 and 3 and associated with RET proto oncogene mutations. Thyroidectomy is done at very early ages of life based on risk level.

\section{Long term follow up}

Children with Differentiated Thyroid Cancer (DTC) may experience adverse psychosocial effects and be non-adherent with thyroid replacement therapy. Attention to these possibilities and supportive counseling as required are important adjuncts in the longterm follow-up of children with DTC. Future studies on the impact of a DTC diagnosis and treatment on quality of life in children are required. Recurrence of DTC in children has been reported as long as 40years after initial therapy. For that reason, children with DTC should be followed for life, albeit with decreasing intensity for those with no evidence for disease.

\section{Acknowledgments}

None.

\section{Conflicts of interest}

Author does not have financial disclosure or conflicts of interest.

\section{Funding}

None.

\section{References}

1. Mussa A, De Andrea M, Motta M, et al. Predictors of Malignancy in Children with Thyroid Nodules. J Pediatr. 2015;167:886-892.

2. Haugen BR, Alexander EK, Bible KC, et al. 2015 American Thyroid Association Management Guidelines for Adult Patients with Thyroid Nodules and Differentiated Thyroid Cancer: The American Thyroid Association Guidelines Task Force on Thyroid Nodules and Differentiated Thyroid Cancer. Thyroid. 2016;26(1):1-133.

3. Gharib H, Papini E, Valcavi R, et al. American Association of Clinical Endocrinologists and Associazione Medici Endocrinologi medical guidelines for clinical practice for the diagnosis and management of thyroid nodules. Endocr Pract. 2006;12(1):63-102.

4. Golpanian S, Perez EA, Tashiro J, et al. Pediatric papillary thyroid carcinoma: outcomes and survival predictors in 2504 surgical patients. Pediatr Surg Int. 2016;32(3):201-208.

5. Bauer AJ, Francis GL. Evaluation and management of thyroid nodules in children. Curr Opin Pediatr. 2016;28(4):536-544. 
6. Francis GL, Waguespack SG, Bauer AJ, et al. Management Guideline for Children with Thyroid Nodules and Differentiated Thyroid Cancer. Thyroid. 2015;25(7):716-759.

7. Baloch ZW, LiVolsi VA, Asa SL, et al. Diagnostic terminology and morphologic criteria for cytologic diagnosis of thyroid lesions: a synopsis of the National Cancer Institute Thyroid Fine-Needle Aspiration State of the Science Conference. Diagn Cytopathol. 2008;36(6):425-437.

8. Cherella CE, Feldman HA, Hollowell M, et al. Natural History and Outcomes of Cytologically Benign Thyroid Nodules in Children. J Clin Endocrinol Metab. 2018;103(9):3557-3565.

9. Marqusee E, Benson CB, Frates MC, et al. Usefulness of ultrasonography in the management of nodular thyroid disease. Ann Intern Med. 2000;133(9):696-700.

10. Goolden AW, Kam KC, Fitzpatrick ML, et al. Oedema of the neck after ablation of the thyroid with radioactive iodine. $\mathrm{Br} J$ Radiol. 1986;59(702):583-586.
11. Sawka AM, Lea J, Alshehri B, et al. A systematic review of the gonadal effects of therapeutic radioactive iodine in male thyroid cancer survivors. Clin Endocrinol (Oxf). 2008;68(4):610-617.

12. Verburg FA, Hanscheid H, Biko J, et al. Dosimetry-guided high-activity ${ }^{(131)}$ I therapy in patients with advanced differentiated thyroid carcinoma: initial experience. Eur J Nucl Med Mol Imaging. 2010;37(5):896-903.

13. Hogan AR, Zhuge Y, Perez EA, et al. Pediatric thyroid carcinoma: incidence and outcomes in 1753patients. J Surg Res. 2009;156(1):167-172.

14. Otto KJ, Lam JS, MacMillan C, et al. Diminishing diagnosis of follicular thyroid carcinoma. Head Neck. 2010;32(12):1629-1634.

15. Layfield LJ, Cibas ES, Gharib H, et al. Thyroid aspiration cytology: current status. CA Cancer J Clin. 2009;59(2):99-110. 